four hours. He continued much the same till June 14th, when he had a tetanic convulsion at 4.45 P.M. and ten cubic centimetres of serum were injected at 6.30 P.M., to be followed at 8 P.M. by another attack. The spasms were controlled by chloroform. Between midnight on the 14th and $5 \mathrm{~A}$.M. on the 15th, at intervals of rather less than an hour, the patient had seven very severe tetanic seizures, in some cases with opisthotonos, during which respiration was seriously interfered with, and chloroform was freely administered, artificial respiration being resorted to during the worst attacks. Bromide and chloral given per rectum produced no apparent benefit.

Any attempt to feed the patient or to touch him at this period brought on a spasm and he was therefore left as quiet as possible till at 5.15 P.M., June 15th, on trying to pass a nasal tube for feeding purposes, another violent convulsion was induced. He was again anæsthetised and 30 grains of chloral hydrate were passed by the stomach tube. This was retained and the patient slept quietly for several hours. $\mathrm{He}$ felt better on waking and was able to take liquid nourishment by the mouth but was unable to separate the jaws. He continued to be more comfortable until 2 P.M. on the 16th, when he had a slight spasm from tarning himself in bed. He was given 15 grains of chloral hydrate by the mouth and was quiet again till 1 A.M. on the 17 th, when he had another slight spasm for which a similar dose was administered. The highest temperature recorded was on the 15 th when it reached $101.6^{\circ} \mathrm{F}$. at 2 P.M. The pulse was 104 The patient sweated profusely during the attacks and thirst was extremely marked. The wound was now dressed with a strong solution of sanitas in the hope of inhibiting the development of fresh organisms.

On June 19th it was decided to try curare and at 6 P.M. one-twelfth of a grain was given subcutaneously. He had a spasm at 1 A.M. on the 20th, for which a further onetwelfth of a grain was injected at 1.20 A.M., after which he remained free till $8.45 \mathrm{~A} . \mathrm{M}$., when another seizure took place for which he was given 20 grains of chloral hydrate at 8.55 A.M. At 4.40 P.M. a fresh attack came on and curare one-sixth of a grain, was injected at 5.40 P.M. He had a slight spasm at 8.30 P.M. and again at 8.45 P.M. 30 grains of chloral hydrate were given by the stomach tube under chloroform. At 9.15 P.M. ten cubic centimetres of serum were injected, but another sharp spasm came on at 11.15 P.M., followed by slight attacks at intervals of about two hours, until at 5 P.M. on the 21 st he had a very severe convulsion, which as usual was controlled by chloroform. A similar event occurred at $1.10 \mathrm{~A} . \mathrm{M}$. on the $22 \mathrm{nd}$ and one-third of a grain of curare was injected at 1.15 A.M. Except for the constant state of rigidity of the muscles he was now fairly comfortable. Slight spasms manifested themselves at 4.40 and 4.50 P.M. on the 22 nd and at 6.5 P.M. he was given half a grain of curare. At 10.20 P.M. 30 grains of chloral hydrate were administered by the stomach tube under chloroform to induce sleep and at 1.35 A.M. on the 23rd two-thirds of a grain of curare were injected. The patient felt better after this, the jaws could be separated slightly, and he was free from spasms, but as a precautionary measure five-sixths of a grain of curare were injected at $1.15 \mathrm{~A}$.M. on June 24 th with steady improvement and the same night at 8.20 one grain of curare was given. The temperature this day was $100^{\circ} 4^{\circ}$, the pulse was 120 , and the respirations were 54. The teeth could now be separated fully a quarter of an inch and in order to see whether any change would occur the curare was discontinued. June 25th passed uneventfully, but at 6.30 P.M. on the 26 th another severe convulsion made its appearance, with close apposition of the teeth once more. At 6.45 P.M. one grain of curare was injected and the same dose was repeated at 1.35 A.M. on the 27 th without recurrence of spasm. The jaws could again be separated as before and accordingly curare was continued once every 24 hours in increasing doses up to two and a half grains at 1.30 A.Mr. on July 1st, when very marked improvement set in. From this date a daily administration of one grain of curare was kept up until the 9th, when he was able to use his jaws to masticate food, and then half a grain till the 20 th, with steady reduction in the tonicity of the muscles. Active treatment was discontinned after July 20th, he developed an excellent appetite, and put on flesh rapidly. The patient was placed out-of-doors on June $27 \mathrm{th}$ in a recumbent position to have the advantage of the bright sunshine and daily afterwards when weather permitted. A month after the onset of tetanus he was able to walk about and on Angust 13th he left the hospital quite well.
Remarks by Dr. ConNoliy and Dr. CuLLLAN, - 'the case presents some features of interest, viz.-(a) Incubation period (seven days). Some recent statistics have placed the mortality at 96 per cent. in cases where tetanus manifests itself under ten days after injury. (b) Number of spasms: 16 severe and 14 less severe, 30 altogether. (o) Marked improvement under treatment with curare and recurrence of the spasms when it was stopped during the active stage of the disease. In all 26 ? grains of curare were given hypodermically. No ill effects on the heart were observed and the patient said that he felt more comfortable and could breathe more easily after the injections.

Mr. W. J. Symes, under whose care the patient was admitted, has kindly permitted us to record these notes.

\section{WEST CORNWALL MINERS' AND WOMEN'S HOSPITAL, REIDUTH.}

CASES OF ABDOMINAI SECTION PERFORMED FOR INTUSSUSCEPTION AND PERFORATING GASTRIC ULCER.

(Under the care of Dr. JoHN H. Tonking.)

IN these cases, which were three in number, one patient suffered from intussusception and the other two from perforating gastric ulcer. The case of intussusception terminated fatally; of the other two patients one recovered and the other succumbed on the eleventh day after an operation for subphrenic abscess. Including these, three operations for perforation, all performed by Dr. Tonking, have taken place at this hospital during the last 12 months.

CASE 1.-The patient was a man, about 40 years of age, who was seized with acute abdominal pain on Jan. 18th. There was great tenderness equally in the appendicular region and in the epigastrium and hot opium fomentations were applied at 1 P.M. At 6 P.M., as no relief was felt, a consultation was held with Dr. Frank Hichens of Redruth, when perforation was diagnosed, and as the man's wife admitted having had considerable difficulty with regard to his food the perforation was considered to be probably in the wall of the stomach, although there was marked appendicular tenderness. The liver dulness was normal and there was no vomiting; the abdomen was absolutely rigid and typical facies was present. At 9 P.M. ether was administered by Dr. William Blackwood and assisted by Dr. Hichens Dr. Tonking opened the abdomen. Gas immediately escaped and a perforation was found at the pyloric end of the stomach close to the lesser curvature. The abdomen was swabbed but no irrigation was used as there was no extravasation. The position rendered tucking in difficult, and partly by turning in and partly by stitching the omentum over the perforation was closed by a double layer of fine silk sutures. A drainage-tube with a gauze wick leading to the perforation was placed in the wound after swabbing the parts dry without irrigation and the wound was closed. The usual rectal feeding was employed for five days with the addition of strychnine when required. The temperature, however, did not come down but remained between $100^{\circ}$ and $101^{\circ} \mathrm{F}$. for a week when dulness was discovered at the right base. This increased and on the tenth day, after exploring with a needle in the ninth interspace, pus was let out by excising a portion of the tenth rib. The temperature still did not come down and the patient died on the next day. There were no stomach symptoms and the abdominal wound had practically healed.

CASE 2.-The patient was a youth, aged 19 years. He was staying in Camborne for Easter Monday and after dinner was walking in the town when he was seized with agonising pain in the abdomen for which each of his friends suggested a different variety of spirit. After taking whisky, brandy, rum, and gin without relief he was put into a cab, in the bottom of which he lay doubled up, and was in this way taken home. Dr. Tonking was informed that he had suffered for months from distress an hour or more after meals. The abdomen was board-like. There was repeated vomiting of material having a spirituous odour. The liver dulness was normal. The patient was removed to the hospital and after arrival there the liver dulness was found to have disappeared. At 8 P.M.-namely, five hours after the attack-ether was administered by Dr. Blackwood and Dr. Tonking, assisted by Dr. Hichens, opened the abdomen. There was an immediate escape of gas and a small perforation of the size of a pea, which was found near the pylorus at the lesser curvature, was tucked in 
and fixed by two rows of silk sutures. The temperature at the time of the operation was $100^{\circ} \mathrm{F}$.; on the next day it was $102^{\circ}$; and on the third day it was $99^{\circ}$, falling gradually to normal by the sixth day. Rectal feeding was employed, together with strychnine given hypodermically. On the fifth day gradually increasing quantities of food began to be given. The drainage-tube was removed on this day and recovery was uneventful. Calomel was given on the fourth day. After one month of milk, plasmon jelly, and similar diet solid food was gradually given. The patient left the hospital after six weeks with no gastric symptoms.

CASE 3.-The patient was aged 11 months and was seized on May 18th with pain in the abdomen like colic. The child was nursed by the mother and a little Mellin's food was given as well. The patient was seen by a medical colleague and the condition was treated by him as colic. On the third day, during the absence of this practitioner, Dr. Tonking was called in and found a child who for three days had been suffering from paroxysmal pain and for the last 24 hours there had been a blood-stained mucoid anal discharge. Per anum a tumour could be felt, the contour of which was suggestive of the cervix uteri. No abdominal tumour could be felt; the abdomen was distended. On the same day (May 21st) the child was admitted into the hospital where ether (Rendle's mask) was administered by Dr. Blackwood and the case was examined with the assistance of Dr. Hichens. No tumour could be felt, a circumstance which was attributed partly to the child being fat and well nourished and partly to the abdominal distension. The abdomen was opened in the middle line and as it was found impossible to deal with the intussusception a cross cut was made towards the left side. After this the intussusception was readily reduced; in fact, on the least pressure it ran up the intestine like a mouse creeping on until within the last six inches, after which every effort (even pressure to partial rupture of the peritoneal coat) failed to reduce it. As reduction was impossible the cæcum was incised and its contents were found to be black and gangrenous. The gangrenous portion was excised, the intention being to suture the ingoing layer to the returning layer (Barker's operation). The child, however, succumbed to the operation owing to the length of time involved and to the unfortunate delay in recognising the condition. The intussusception was of the ileo-cæcal variety, the apex being the ileo cæcal valve.

Remarks by Dr. TonkIng,-The last case shows the ease of reduction of an intussusception up to a certain point and the uselessness of water or air injection to deal with the last few inches in an intussusception if there is any marked swelling. It likewise demonstrates the ease of reduction if such cases are recognised at once.

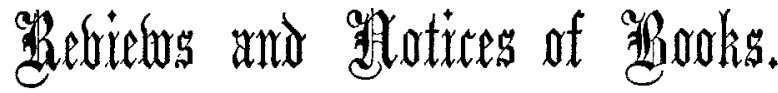

The Examination of Waters and Water-Supplies. By JoHN C. Thresh, D.Sc. Lond., M.D. Vict., D.P.H. Cantar. London: J. \& A. Churchill. 1904. Pp. 460. Price 14s

THE value of chemical and bacteriological analysis respectively in regard to the determination of the purity of water-supplies has been doubted by various observers from time to time. The first opponents to bacteriological analysis were generally the old school of analytical chemists who pinned their faith to chemical methods. On the other hand, not a few bacteriologists at one time looked upon the chemical analysis of potable waters as without value. 'The fact is that both chemical and bacteriological methods have their discrepancies and this view has now come to be shared by all concerned. There are instances in which it has been known that slight contamination of a water has taken place and yet chemical analysis has given practically negative results, while organisms of the colon series were readily detected by bacteriological methods. Owing to the splendid investigation that has been directed to the isolation and recognition of the flora of sewage it would seem that the detection of pollution so slight as 1 part per $1,000,000$ can ke effected by bacteriological means. On the other hand, if a considerable time has elapsed since the pollution took place the recognition of impurity by bacteriological processes becomes uncertain. The same applies to chemical analyses, though in this instance, in spite of purifying influences at work, the products of combustion, so to speak, may be found. Thus nitrogen previously existing in organic matter and ammonia may be ultimately present as nitrate. In surface water it is certain that ammonia and nitrites are scarcely ever present to any extent without sewage contamination. Valuable as may be the indications given in a carefully conducted chemical analysis, one very important fact must ever stand out in favour of bacteriological examination and that is that in the case of filtered supplies the purifying work of the filter-bed is essentially bacteriological and therefore the efficiency of the filter-bed can only be controlled by instituting bacteriological analyses of the effluent. Dr. Thresh has had the advantage of considerable practical experience with both methods of analysis and in his book on the subject he sees no reason for abandoning chemical methods. "In recent years," he says, "bacteriology has come to the aid of chemistry, and there is now a general opinion that a bacteriological examination is more important than a chemical analysis. This is undoubtedly true in some cases but not in all. A properly made bacteriological examination may often afford indications of pollution which no chemical analysis could possibly detect, but $I$ am afraid that the inferences drawn from the results of many so-called bacteriological examinations are often as fallacious as those derived from the results of chemical analyses. When we find that waters used for long periods by large communities are condemned by bacteriologists as being dangerously polluted, and that the results obtained from the same water by different bacteriologists differ to an extent which is impossible in a chemical analysis, our faith in bacteriological examination is somewhat shaken. In any case a proper bacteriological examination is far more tedious and more troublesome to perform than a chemical analysis, and the results are even more difficult to correctly interpret." He very properly, however, emphasises the importance of making a microscopical and biological examination of suspended matter in drinking water for "very often such an examination reveals more quickly and certainly the character of a water and some defects in its source than either a chemical or bacteriological analysis. In several instances such an examination has led to the disccvery of sources of pollution which had been overlooked at a careful inspection."

Dr. Thresh's remarks upon the importance of making careful inspection of the source of supply should be very carefully considered by those engaged in analysis. Often the examination of the source of supply has given him far more important information than could be obtained from the analytical results. The examination of the source in numerous instances in which the supplies were the cause of outbreaks of disease was the means of affording information without which the chemical, bacteriological, or microscopical examination of the water "could not have been correctly interpreted." Part I. of his book, since it deals with the examination of the sources from which the water is derived, is therefore of the greatest importance. In Part II. the various methods of examining water and the interpretation of the results are very thoroughly considered and in Part III. the analytical process and methods of examination are set forth in practical detail. The chapter on Bacteriological Examination of Water will serve as an eminently practical guide to the bacteriologist. Dr. Thresh has wisely kept within the limits of the application of bacteriology to the differentiation of pure from polluted waters and points out concisely and clearly the lines upon which it is safe to proceed. In choosing this course he is supported by the evidence 